\title{
Ambient TSP concentration and dustfall variation in Urumqi, China
}

\author{
XiaoXiao ZHANG ${ }^{1,2^{*}}, \mathrm{Xi} \mathrm{CHEN}^{1}$, YuHong GUO ${ }^{2,3}$, ZiFa WANG $^{2}$, LianYou LIU ${ }^{4}$, Cottle PAUL ${ }^{5}$, ShengYu $\mathrm{LI}^{1}$, \\ HuaWei $\mathrm{Pl}^{1,3}$ \\ ${ }^{1}$ State Key Laboratory of Desert and Oasis Ecology, Xinjiang Institute of Ecology and Geography, Chinese Academy of Sciences, \\ Urumqi 830011, China; \\ ${ }^{2}$ State Key Laboratory of Atmospheric Boundary Layer and Atmospheric Chemistry, Institute of Atmospheric Physics, Chinese \\ Academy of Sciences, Beijing 100029, China; \\ ${ }^{3}$ University of Chinese Academy of Sciences, Beijing 100049, China; \\ ${ }^{4}$ Key Laboratory of Environmental Change and Natural Disaster, Ministry of Education, Beijing Normal University, Beijing \\ 100875, China; \\ ${ }^{5}$ Department of Earth, Ocean and Atmospheric Sciences, University of British Columbia, Vancouver V6T 1Z2, Canada
}

\begin{abstract}
Total suspended particulate (TSP, particle diameter $\leq 100 \mu \mathrm{m}$ ) was the dominant air pollutant and significantly influenced local air quality. In this paper, we investigated the interannual and seasonal variations of TSP and dustfall of the atmosphere over Urumqi, the capital city of Xinjiang Uygur autonomous region, northwestern China, basing on environmental monitoring records and meteorological data from 1986-2012. The results showed that during the study period, annual average TSP concentration decreased from 716 to $260 \mu \mathrm{g} / \mathrm{m}^{3}$, with an average level of $422.9 \mu \mathrm{g} / \mathrm{m}^{3}$, while dustfall intensity reduced from 350.4 to $166.6 \mathrm{t} /\left(\mathrm{km}^{2} \cdot a\right)$, with an average level of 259 $\mathrm{t} /\left(\mathrm{km}^{2} \cdot \mathrm{a}\right)$. Over $50 \%$ of the annual pollution days were induced mainly by TSP. Spring and winter had relatively higher dustfall intensities, and dense traffic and residential areas had the highest dustfall intensities in the Urumqi metropolitan area. With an annual average precipitation of less than $300 \mathrm{~mm}$, atmospheric particulates in Urumqi could be hardly removed through wet deposition. During spring and summertime prevailing winds from northwest and northeast could carry aeolian dust particles from sandy deserts to Urumqi. Aeolian dusts from deserts would remain to be a priority regarding air pollution control in arid oasis cities.
\end{abstract}

Keywords: total suspended particle; dust deposition; desert; atmospheric environment

Citation: XiaoXiao ZHANG, Xi CHEN, YuHong GUO, ZiFa WANG, LianYou LIU, Cottle PAUL, ShengYu LI, HuaWei PI. 2014. Ambient TSP concentration and dustfall variation in Urumqi, China. Journal of Arid Land, 6(6): 668-677. doi: 10.1007/s40333-014-0069-6

Airborne dust is a notable contributor to air pollution in northern China and has significant impacts on the environment in eastern Asia (Husar, 2001; Xuan et al., 2002). Over the past few decades, the emission, transportation and deposition of dust have received increasing attention (Derbyshire et al., 1998; Sassen, 2002; Uno et al., 2009; Groll, 2013). Numerous reports have suggested that dust from central Asia has caused dust deposition in Korea, Japan, USA and across the northern Pacific, as well as traces in ice and snow cores in Greenland (Prospero et al., 1989;
Leinen et al., 1994; Yu et al., 2012). One of the main dust sources in Asia is the Taklamakan Desert located in Xinjiang Uygur autonomous region, northwestern China (Okada and Kai, 2012).

When winds are sufficiently strong in deserts, dust particles are entrained by wind shear at the surface and transported by advection and turbulent diffusion. Finally, they are deposited through dry and wet removal processes (Shao, 2000). This cycle has a significant impact on the atmosphere. Mineral aerosols associated with trace elements are carried by strong winds, and

*Corresponding author: XiaoXiao ZHANG (E-mail: zhangxx@ms.xjb.ac.cn) Received 2013-10-08; revised 2013-12-02; accepted 2014-02-21

(C) Xinjiang Institute of Ecology and Geography, Chinese Academy of Sciences, Science Press and Springer-Verlag Berlin Heidelberg 2014 
then deposited to populated regions, resulting in reduced visibility and substantially contributing to air pollution. Currently, major oasis cities in northwestern China, such as Urumqi, are undergoing rapid development due to urbanization and population growth (Chen et al., 2009; Mamtimin and Meixner, 2011; Wang et al., 2012). For the past several decades, Urumqi has suffered from heavy dust haze $(\mathrm{Li}$ et al., 2006), and it is vulnerable to natural dust emissions from the arid and semi-arid desert areas of Xinjiang.

Recently, some studies have been carried out analyzing the chemical pollution and mineral dust components in the atmosphere above Urumqi. It was reported that the average $\mathrm{PM}_{2.5}$ (particle diameter $\leq 2.5$ $\mu \mathrm{m})$ and TSP (particle diameter $\leq 100 \mu \mathrm{m}$ ) concentrations in the winter of 2007 were 187 and 385 $\mathrm{mg} / \mathrm{m}^{3}$ with maxima of 487 and $1,313 \mathrm{mg} / \mathrm{m}^{3}$, respectively. These levels were 12 times higher than the U.S. EPA standard for $\mathrm{PM}_{2.5}$, and three times higher than China's National Ambient Air Quality Standard for TSP (Li et al., 2008). According to the observations by Mamtimin and Meixner (2011), monthly mean $\mathrm{PM}_{10}$ (particle diameter $\leq 10 \mu \mathrm{m}$ ) concentrations in Urumqi from 2000-2006 were between 150 and $240 \mu \mathrm{g} / \mathrm{m}^{3}$. Dong et al. (2011) studied the physicochemical characteristics of mineral dust particles in the precipitation of the Urumqi River Valley and indicated that aerosol dust in the precipitation was very sensitive to the seasonal change of the regional atmospheric environments in central Asia. However, the research on a long-term influence of TSP and dustfall variations specifically for the atmospheric environment over the dry, populated city of Urumqi is still scarce and inadequate. A study on the impact of dust aerosols that improves the understanding of how ambient TSP and dustfall influence the oasis atmosphere is critical to local residents because it could lead to significant improvements in urban air quality.

In this paper, we systematically investigated the impacts of ambient TSP and dustfall on the atmosphere through a long-term time series and statistical analyses basing on data from environmental monitoring stations and observations over the past three decades. Furthermore, the changes in seasonal precipita- tion and wind frequency as well as their possible associations with TSP and dustfall in Urumqi were also discussed.

\section{Study area}

Urumqi ( $\left.42^{\circ} 45^{\prime} 32^{\prime \prime}-44^{\circ} 08^{\prime} 00^{\prime \prime} \mathrm{N}, 86^{\circ} 37^{\prime} 33^{\prime \prime}-88^{\circ} 58^{\prime} 24^{\prime \prime} \mathrm{E}\right)$, which is located in northwestern China, is the capital city of Xinjiang Uygur autonomous region. It is flanked by the Gurbantunggut Desert in Junggar Basin to the north and rest on the northern foothills of the eastern Tianshan Mountains (Fig. 1). The city was built along a river valley near Bogda Mountain which boasts an elevation of $5,545 \mathrm{~m}$ asl. The regional climate is semi-arid, with an annual average precipitation of about $300 \mathrm{~mm}$ and annual average wind velocity of approximately $2.5 \mathrm{~m} / \mathrm{s}$. In 1998, Urumqi was assessed as one of the ten worst polluted cities in the world in terms of air pollution (Mamtimin and Meixner, 2007) and its total population has rapidly increased from $1.20 \times 10^{6}$ in 1981 to $2.43 \times 10^{6}$ in 2010 (Urumqi Municipal Bureau of Statistics, 2013).

\section{Materials and methods}

The TSP and dustfall data were collected from 12 environmental monitoring stations in the Urumqi metropolitan area (Fig. 2). Airborne TSP samples were taken by an air sampler with fine fiberglass films at $1.5 \mathrm{~m}$ above the ground. Daily TSP concentration data were obtained by the arithmetic mean of at least four measurements, and the sampling time for every measurement lasted longer than an hour. TSP concentration was expressed in $\mathrm{mg} / \mathrm{m}^{3}$ as the mass of particulate matter per unit volume of atmosphere (MEP, 1995). Dustfall was determined by the gravimetric method at monthly intervals. Dust samples were collected with cylindric glass vessels (three replicates) filled with glycol $\left(\mathrm{C}_{2} \mathrm{H}_{6} \mathrm{O}_{2}\right)$, at $10 \pm 1 \mathrm{~m}$ above ground. The glass vessel is $15 \mathrm{~cm}$ in diameter and $30 \mathrm{~cm}$ in depth. All the dust samples were oven-dried at $105^{\circ} \mathrm{C}$, and then weighed. Dustfall intensity was expressed as the mass of dust settled naturally per unit area over a certain unit time, in $\mathrm{t} /\left(\mathrm{km}^{2} \cdot \mathrm{a}\right)$ (MEP, 1994).

The daily API (Air Pollution Index) data were obtained from statistics published by the Ministry of Environmental Protection of China (http://datacenter. 


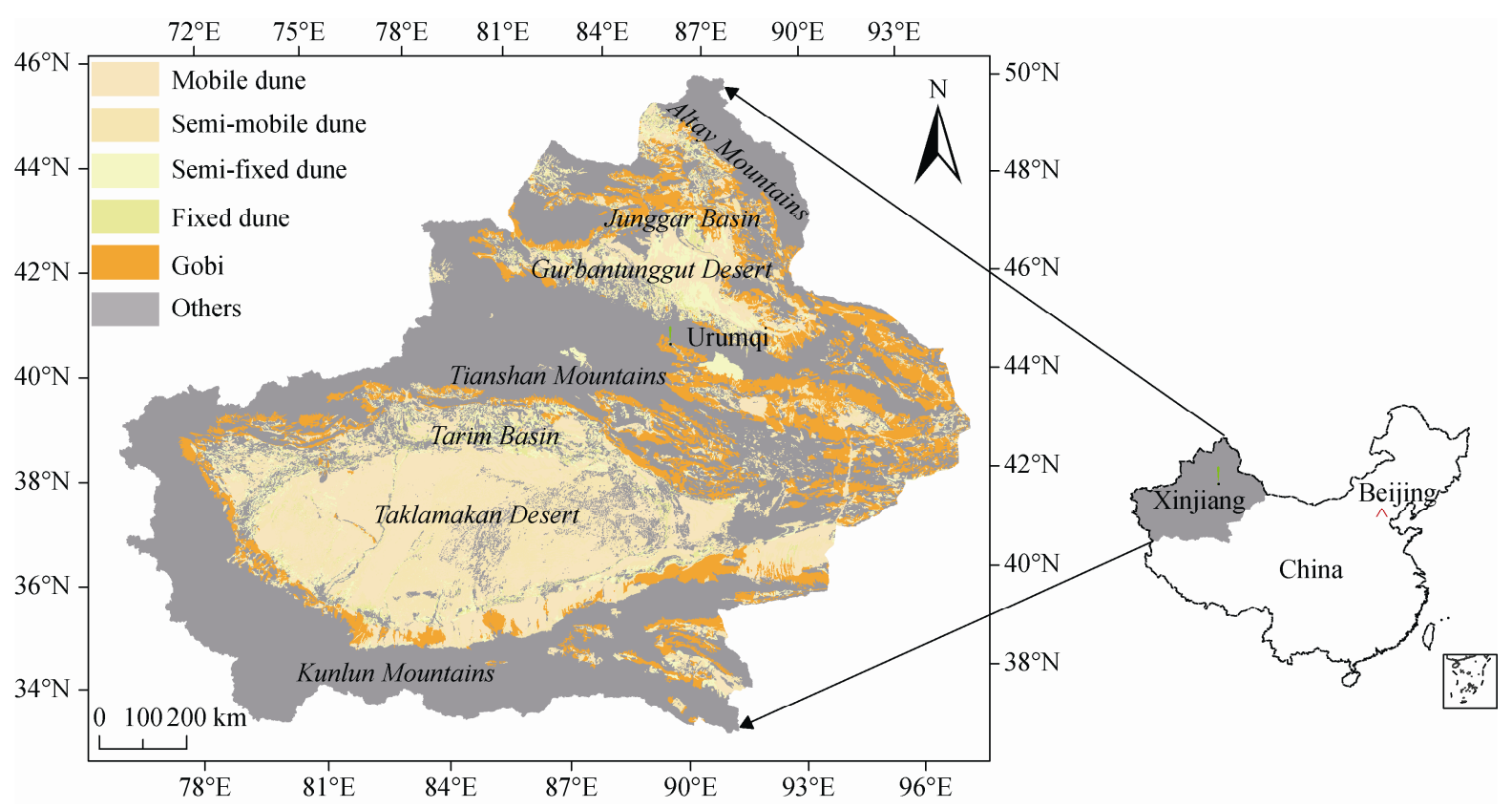

Fig. 1 Location of the study area (Urumqi) and its surrounding desert environment

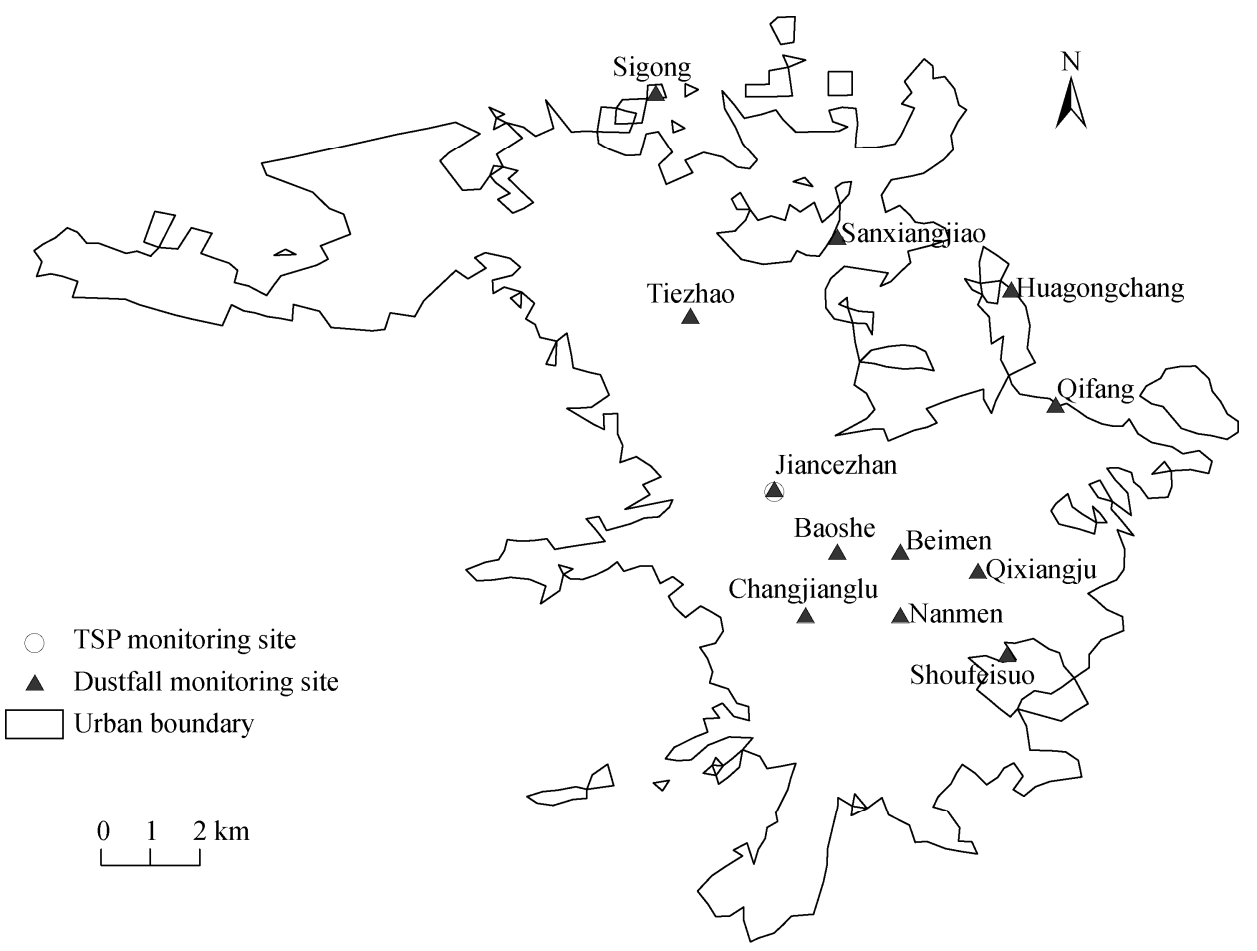

Fig. 2 Distribution of environmental monitoring stations in the Urumqi metropolitan area

mep.gov.cn). The meteorological data, including precipitation, wind speed, wind direction, etc., were collected from the China Meteorological Data Sharing Service System (http://cdc.cma.gov.cn). The desert distribution dataset was provided by the Environ- mental and Ecological Science Data Center for Western China sponsored by the National Natural Science Foundation of China (http://westdc.westgis.ac.cn). In this paper, the percentages of particle pollution days per year and per month were used to quantify the im- 
pact of TSP pollution on the atmospheric environment in Urumqi.

\section{Results and discussion}

\subsection{TSP concentration and dustfall intensity}

Urumqi is in the middle of two dust sources: the Taklamakan Desert and the Gurbantunggut Desert, from which dust particles are easily transported by the wind. Figure 3 depicts the changes in annual average TSP concentration and dustfall intensity in Urumqi from 1986 to 2012. The annual TSP concentration changed within a range of roughly $300-700 \mu \mathrm{g} / \mathrm{m}^{3}$, with a maximum of $716 \mu \mathrm{g} / \mathrm{m}^{3}$ in 1990 and a minimum of $260 \mu \mathrm{g} / \mathrm{m}^{3}$ in 2005 . In the late $1980 \mathrm{~s}, 1990 \mathrm{~s}$ and $2000 \mathrm{~s}$, the annual average TSP concentrations were 541, 464 and $338 \mu \mathrm{g} / \mathrm{m}^{3}$, respectively. During the same period, the annual average dustfall intensity in Urumqi decreased from 350 to $167 \mathrm{t} /\left(\mathrm{km}^{2} \cdot \mathrm{a}\right)$. In the $1980 \mathrm{~s}, 1990 \mathrm{~s}$ and $2000 \mathrm{~s}$, the annual average dustfall intensity was 276, 306 and $222 \mathrm{t} /\left(\mathrm{km}^{2} \cdot \mathrm{a}\right)$, respectively. It can be seen clearly that the atmospheric environment with regard to dust pollution has improved since 1986 and a jointly decreasing trend was observed between dustfall intensity and TSP concentration. Generally, the average annual concentrations of TSP have degraded in three stages: 1986-1990, 1991-2001 and 20022012. The dustfall intensity dropped abruptly in 2002 after remaining stable for several years. At the end of 2012, the average annual TSP concentration and dustfall intensity in Urumqi decreased by more than $20 \%$ and $25 \%$, respectively. This atmospheric improvement might be attributed to two main factors: One is that the local government created and enforced an energy conservation policy beginning in the later 1990s, funded extensively by the 'Blue Sky' project. Massive conversion from coal to natural gas consumption was implemented, which achieved significant progresses in air pollution control (Xinjiang Department of Environmental Protection, 2012). Another factor was due to a decrease in the frequency of dust storm outbreaks in the arid and semi-arid desert areas of Xinjiang during the past several decades (Details are discussed in Section 3.2).

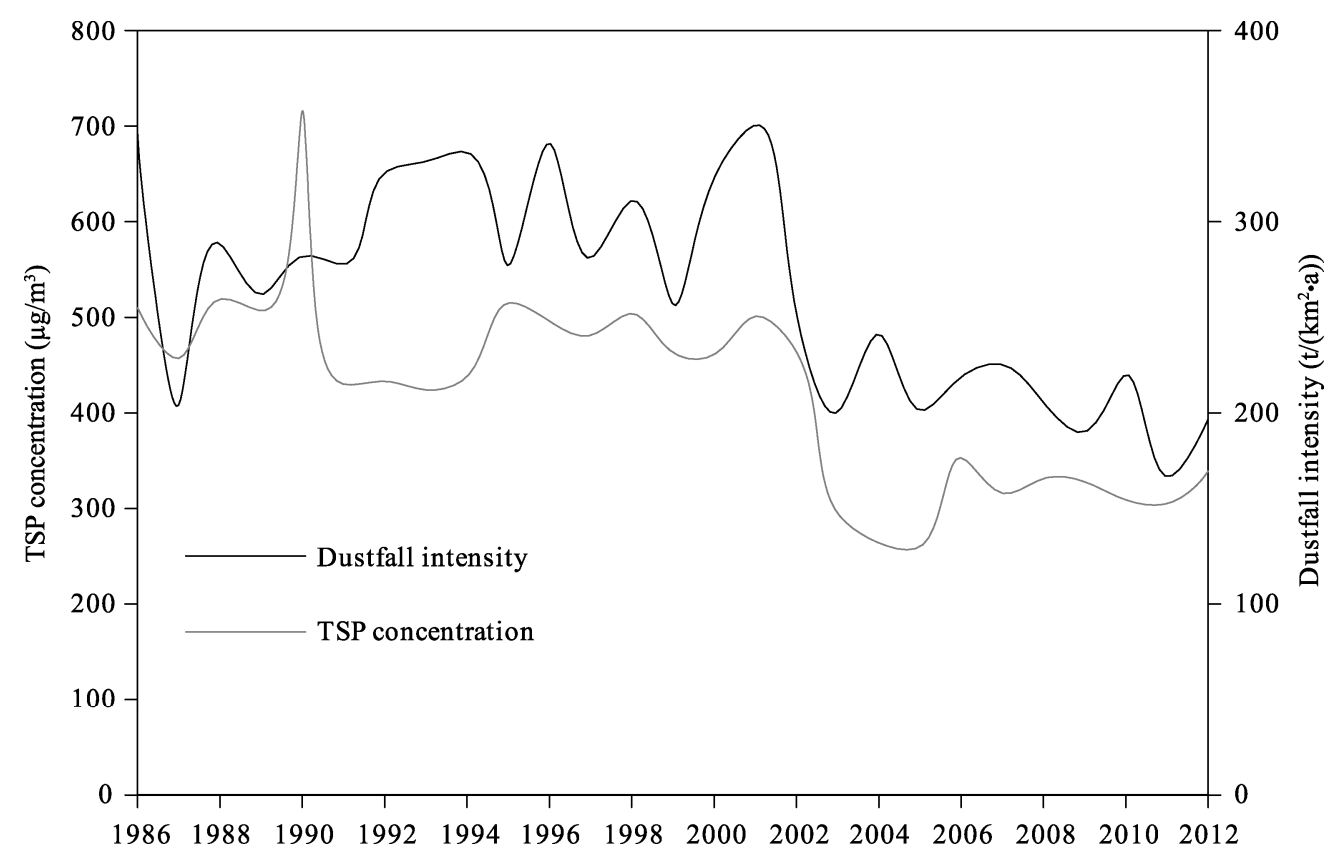

Fig. 3 Changes in annual average TSP concentration and dustfall intensity in Urumqi from 1986 to 2012

The basic background information for environmental monitoring stations in the Urumqi metropolitan area as well as the average annual dustfall intensity from 1986 to 2012 for each station were listed in
Table 1. The comparison of the 12 stations revealed higher dustfall intensities in dense traffic and residential areas. Dustfall intensity showed a high degree of spatial variability, which ranged from $127.9 \mathrm{t} /\left(\mathrm{km}^{2} \cdot \mathrm{a}\right)$ 
in Sigong to $374.5 \mathrm{t} /\left(\mathrm{km}^{2} \cdot \mathrm{a}\right)$ in Shoufeisuo. The dustfall intensity at the edge of the metropolitan area was around $200 \mathrm{t} /\left(\mathrm{km}^{2} \cdot \mathrm{a}\right)$ except for Sigong in the north. Stations with the heaviest dust deposition were Shoufeisuo and Tiezhao, which were respectively located in a dense traffic area and residential center. The average annual dustfall intensity from 1986 to 2012 in Urumqi city amounted to $259 \mathrm{t} /\left(\mathrm{km}^{2} \cdot a\right)$. Generally, it's assumed that particle pollution was mainly attributed to locally sourced aerosols generated by automobile vehicles or domestic combustion combined with natural sources like desert dust (Yang and Chen, 2002;
Bogo et al., 2003; Liang et al., 2008; Wang et al., 2010).

The distribution of seasonal dustfall intensity was useful to assess possible pollution sources and identify periods most prone to dust pollution. Figure 4 indicates that dustfall intensity in Urumqi was highest in spring (March-April-May, or MAM), followed by winter (December-January-February, or DJF) and autumn (September-October-November, or SON), with summer (June-July-August, or JJA) being lowest. Moreover, there was no apparent distinction in the dust deposition in autumn by comparison with winter.

Table 1 The environmental monitoring stations used in this study

\begin{tabular}{|c|c|c|c|c|}
\hline No. & Station name & District & Function zone & Dustfall intensity $\left(\mathrm{t} /\left(\mathrm{km}^{2} \cdot \mathrm{a}\right)\right)$ \\
\hline 1 & Shoufeisuo & Tianshan & Dense traffic area & 374.5 \\
\hline 2 & Beimen & Tianshan & Dense traffic area & 305.8 \\
\hline 3 & Jiancezhan & Sayibak & Dense traffic area & 291.1 \\
\hline 4 & Tiezhao & Xinshi & Residential area & 324.9 \\
\hline 5 & Changjianglu & Sayibak & Dense traffic area & 241.2 \\
\hline 6 & Baoshe & Sayibak & Commercial area & 219.7 \\
\hline 7 & Huagongchang & Shuimogou & Industrial area & 256.1 \\
\hline 8 & Qixiangju & Tianshan & Residential area & 253.0 \\
\hline 9 & Nanmen & Tianshan & Residential area & 261.9 \\
\hline 10 & Qifang & Shuimogou & Industrial area & 235.9 \\
\hline 11 & Sanxiangjiao & Xinshi & Industrial area & 216.2 \\
\hline \multirow[t]{2}{*}{12} & Sigong & Xinshi & City outskirt & 127.9 \\
\hline & Total average & & & 259.0 \\
\hline
\end{tabular}

Note: dustfall intensities were calculated with annual averages from 1986 to 2012.

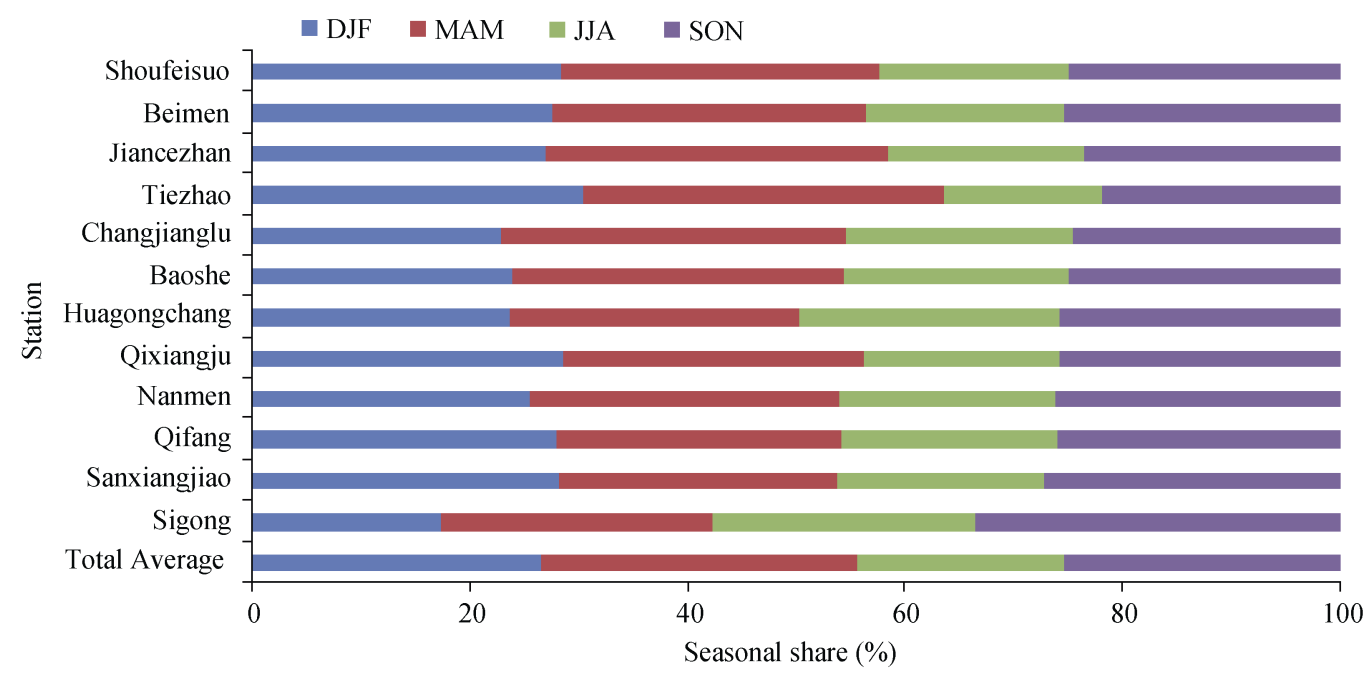

Fig. 4 Seasonal distribution of dustfall intensity at 12 monitoring stations in Urumqi from 1986 to 2012 
In the spring, the main sources of dust in Urumqi were from neighboring farmlands and deserts ( $\mathrm{Li}$ et al., 2008). The particulates generated by automobiles and secondary blowing dust might be additional factors affecting the dust intensity and distribution in Urumqi (Li et al., 2008; Li et al., 2010).

\subsection{Influence of TSP on air quality}

In China, most northern cities suffer seasonal dust haze and dust storms. The dust pollution not only damages human health, but also changes regional radiative forces and surface albedo (IPCC, 2007). In March 2000, the Chinese government launched an air quality monitoring network in major Chinese cities. Figure 5 depicts daily air quality levels in Urumqi from 2001 to 2012 . It shows that the primary source of air pollution in Urumqi was TSP for all seasons. Heavy TSP pollution significantly affected the atmosphere of Urumqi. The most severe air pollution events happened primarily in spring and winter which are with the worst air quality of the year. On the whole, TSP pollution in spring has apparently decreased since 2002. Over the past three decades, the frequency of dust storms had decreased substantially in northern China (China Meteorological Administration, 2010). Therefore, the TSP pollution mitigation in spring might be attributed to a reduction in dust storm frequency in Xinjiang in the late $20^{\text {th }}$ century (He et al., 2003; Wei et al., 2004; Amina and Dilinuer, 2011). Summer showed the best air quality among the four seasons, with an average daily API of less than 100, which ranked within excellent air quality (0-50) or slight TSP pollution (51-100) on the Chinese API scale. In autumn, the weather gradually becomes cold and windy, and the air quality is relatively good compared to that of the frigid winter season. Below-freezing winters in northwestern China, especially Urumqi, require substantial heating for homes. A widespread temperature inversion occurs in the city throughout the winter (Mamtimin and Meixner, 2011). Therefore, air pollution could be trapped beneath the inversion for long periods, which is likely the cause of high TSP levels in the atmosphere (Fig. 5).

Figure 6 reflects that the share of average annual TSP pollution days was over 54\% from 2001 to 2012 , with the exception of 2005 , and the monthly share from April to October was over 90\%. The share of annual average TSP pollution days showed an incremental rise in the last six years, staying above $75 \%$. There were considerable variations among seasons with average monthly shares of TSP pollution days ranging from $46 \%$ to $98 \%$ and dropping sharply in winter compared to relatively high values in spring, summer and autumn (Fig. 6b). This phenomenon of air pollution levels of TSP decreasing in winter (Fig.5 and Fig. 6b) is attributed to the heating process of coal combustion which produces large amounts of sulfur-containing pollutants ( $\mathrm{Li}$ et al., 2008). Therefore, the share of average monthly $\mathrm{SO}_{2}$ pollution days was rising rapidly during cold wintertime. Although the monthly share of TSP was lower in winter than in other seasons, particle pollution still severely affected the atmosphere of Urumqi year-round.

\subsection{Factors of influencing TSP and dust deposition}

Figure 7 depicts the seasonal change of daily average TSP concentration and precipitation in Urumqi from 2001 to 2012. It showed that daily TSP concentrations changed with seasons. TSP concentrations were higher in spring and winter than in summer and autumn. However, spring is the season in which sand and dust storms occur most frequently in Xinjiang. During these periods, particles with larger diameters are deposited at an increased rate near the edge of deserts through gravitational settling. In contrast, finer particles are transported over longer distances to oasis regions such as Urumqi. During spring and summer, precipitation plays a vital role in removing dust particles since wet deposition removes dust particles floating in the atmosphere more efficiently ( $\mathrm{Li}$ and Wang, 2007). Urumqi is cold and dry in winter with a mean monthly precipitation of around $12-30 \mathrm{~mm}$ and minimum surface temperatures reaching a frigid $-28.1--29.0^{\circ} \mathrm{C}$. Annually, heating within the city is available over six months, from 15 October to 15 April (Li et al., 2007). This lengthy period resulted in gross consumption of fossil fuels, and caused a high level of particulate pollution in the late autumn and winter. It's estimated that annual coal consumption in 2010 was $1.6 \times 10^{7}$ tons (Xinjiang Statistical Bureau, 2012). Although snowfall precipitation occasionally occurred throughout the winter and apparently 

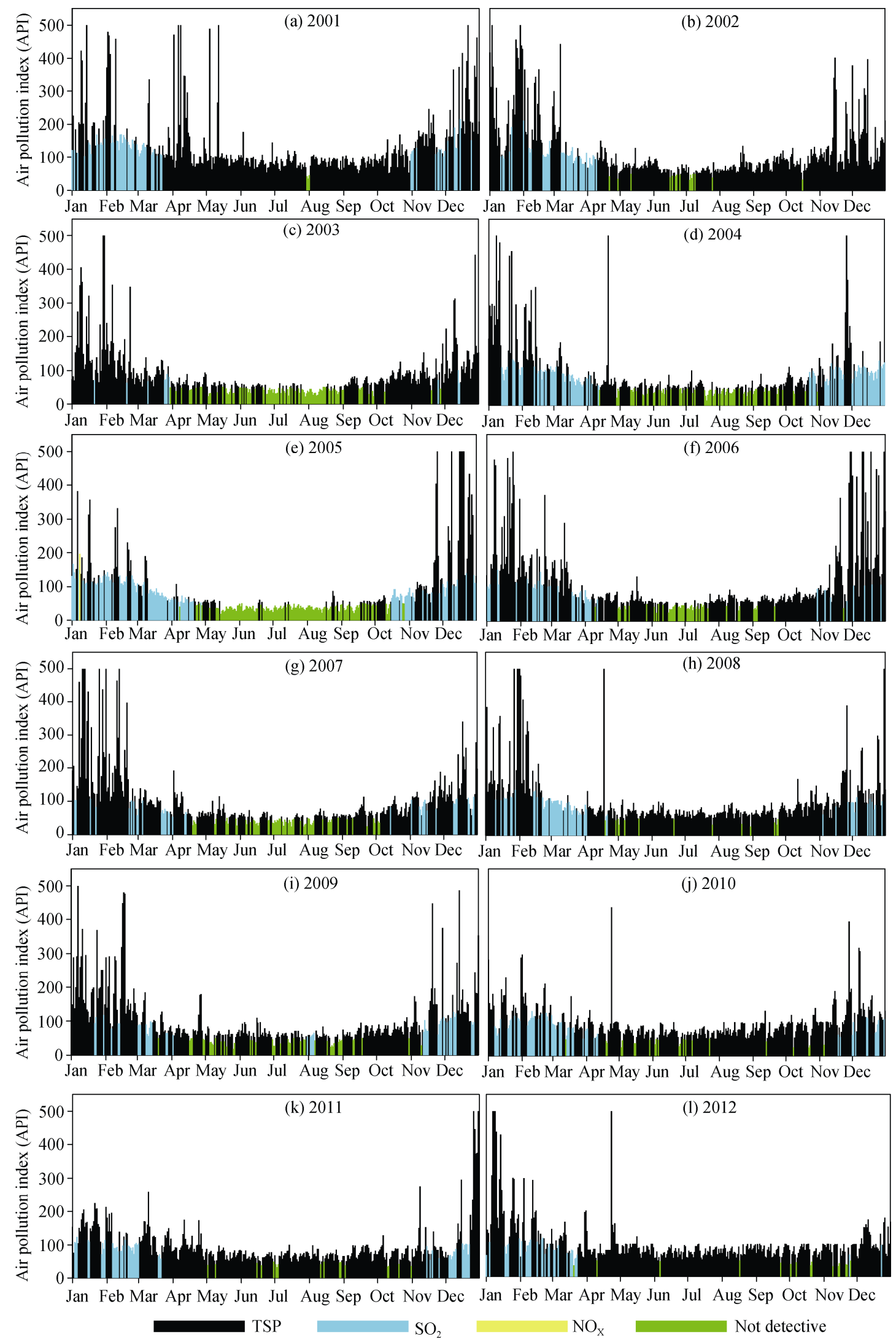

Fig. 5 Air pollution index (API) and major air pollutants in Urumqi city from 2001 to 2012 


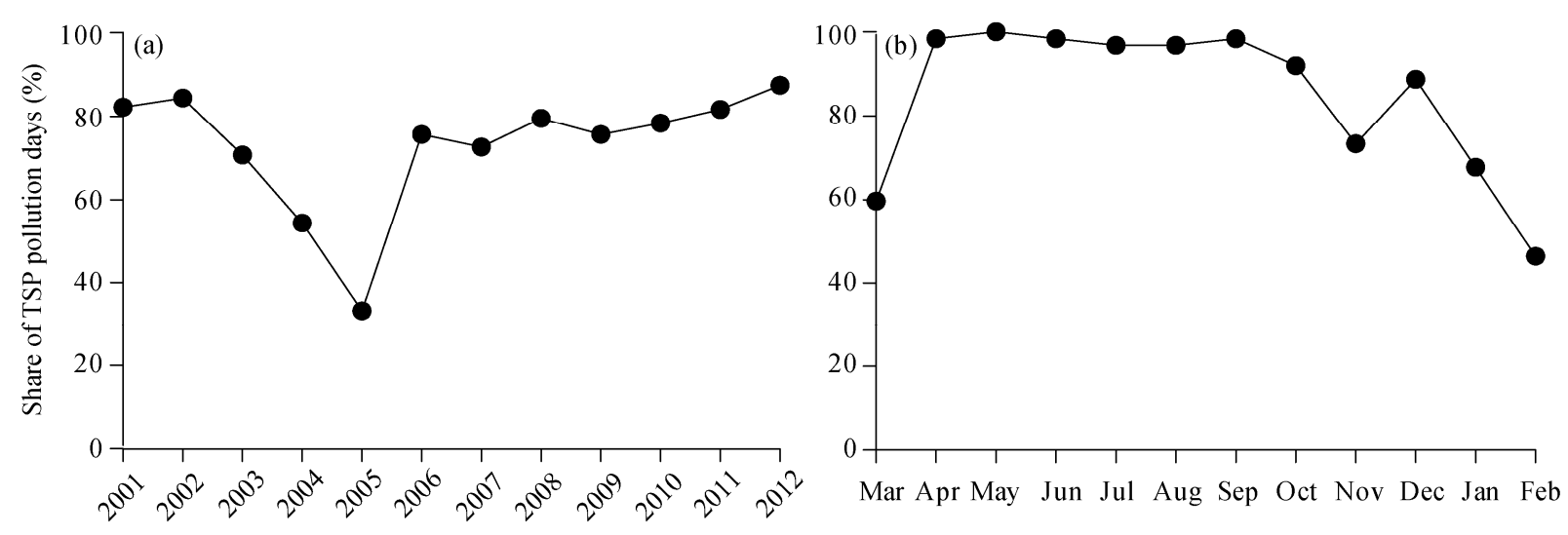

Fig. 6 Changes in annual (a) and monthly (b) shares of TSP pollution days from 2001 to 2012

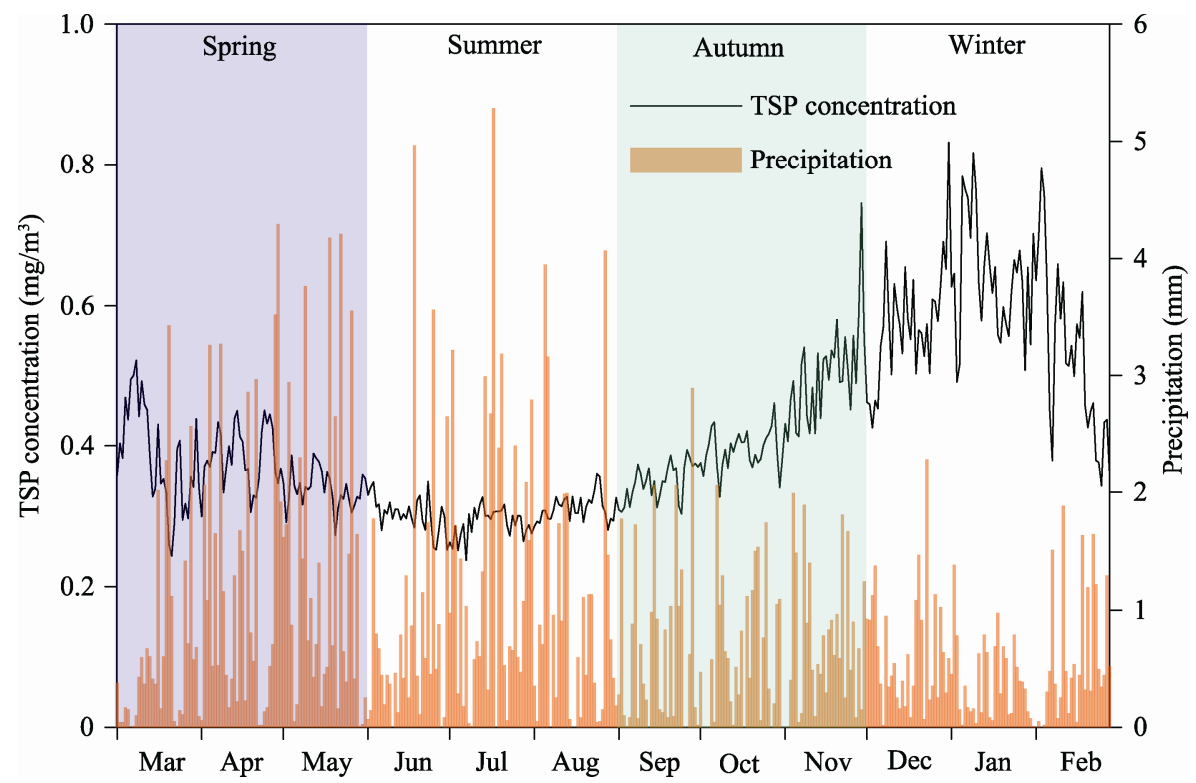

Fig. 7 Seasonal change in average daily TSP concentration and precipitation in Urumqi from 2001 to 2012

improved air quality within 1-2 days (Li and Wang, 2007), a comprehensive reduction of persistent and continuous particulate pollution in the atmosphere is still necessary.

Wind plays an important role in carrying particles over a long distance in arid and semi arid areas (Shao, 2000; Kumar, 2008). The frequency and distribution of maximum wind velocities in Urumqi in spring, summer, autumn and winter from 2001 to 2012 are shown in Fig. 8. Maximum wind velocity of different seasons was mainly originating from the northeast and southwest in winter, northwest and northeast in spring, northwest in summer, and southwest in autumn, respectively. With a mean altitude of about $800 \mathrm{~m}$ asl,
Urumqi is surrounded by the Tianshan Mountains with the mountain peak topping over $5,000 \mathrm{~m}$ asl in every direction except north, creating a valley wherein the city lies. In winter, air pollution is not easily removed since Urumqi was built along a northeast to southwest river valley with northwest and southwest winds blocked by the Tianshan Mountain Range that houses the valley. Consequently, the air pollution can hover for long periods. Wind direction in spring blows from the north, often carrying sand and dust from the nearby Gurbantunggut Desert, exasperating the effect. This result corresponds to points of view in relative studies ( $\mathrm{Li}$ et al., 2008; Mamtimin and Meixner, 2011). 

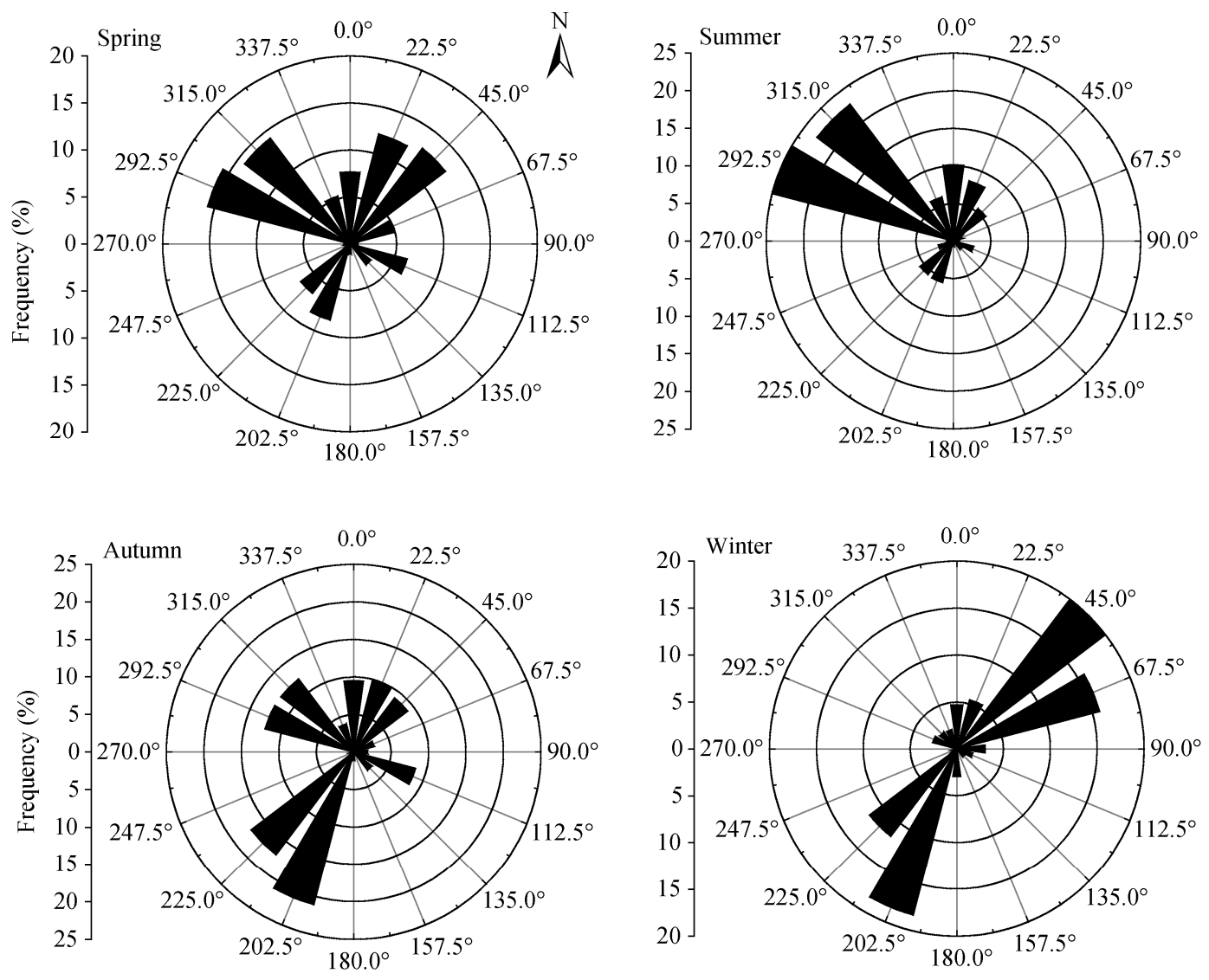

Fig. 8 Seasonal frequency and distribution of maximum wind velocity in Urumqi from 2001 to 2012

\section{Conclusions}

From 1986 to 2012, average annual TSP concentration and dustfall intensity in Urumqi decreased by $63.6 \%$ and $52.4 \%$, respectively. Although air quality has been obviously improved and TSP concentration and dustfall intensity decreased accordingly, the atmospheric environment of Urumqi is still affected by airborne particulates. In arid climatic conditions, precipitation plays a limited role in removing airborne particles. Under sand and dust storms, strong winds blow large amounts of aeolian dust particles from desert areas to the metropolitan region. Aeolian dust from arid deserts would remain a dominant contributor to air pollution in oasis cities.

\section{Acknowledgements}

This work was supported by the West Light Foundation of the Chinese Academy of Sciences (XBBS201104), the National Natural Science Foundation of China (41301655), the Coopera- tion Team of the Chinese Academy of Sciences (granted to Prof. Xi CHEN, Xinjiang Institute of Ecology and Geography, the Chinese Academy of Sciences), and the Open Funds of the State Key Laboratory of Atmospheric Boundary Layer and Atmospheric Chemistry, China (LAPC-KF-2013-17).

\section{References}

Amina A, Dilinuer A. 2011. Analysis of sandstorm disaster in Xinjiang in recent 50 years. Journal of Arid Land Resources and Environment, 25(8): 118-121.

Bogo H, Otero M, Castro P, et al. 2003. Study of atmospheric particulate matter in Buenos Aires city. Atmospheric Environment, 37(8): 1135-1147.

Chen X, Yan J F, Chen Z, et al. 2009. A spatial geostatistical analysis of impact of land use development on groundwater resources in the Sangong Oasis Region using remote sensing imagery and data. Journal of Arid Land, 1(1): 1-8.

China Meteorological Administration. 2010. Yearbook of China Meteorological Disasters. Beijing: China Meteorological Press, 41.

Derbyshire E, Meng X, Kemp R A. 1998. Provenance, transport and characteristics of modern aeolian dust in western Gansu Province, China, and interpretation of the quaternary loess record. Journal of Arid Environments, 39: 497-516. 
Dong Z W, Li Z Q, Edwards R, et al. 2011. Temporal characteristics of mineral dust particles in precipitation of Urumqi River Valley in Tian Shan, China: a comparison of alpine site and rural site. Atmospheric Research, 101: 294-306.

Groll M, Opp Chr, Aslanov I. 2013. Spatial and temporal distribution of the dust deposition in Central Asia - results from a long term monitoring program. Aeolian Research, 9: 49-62.

He Q, Yang Q, Li H J. 2003. Variations of air temperature, precipitation and sand-dust weather in Xinjiang in past 40 years. Journal of Glaciology and Geocryology, 25(4): 423-427.

Husar R B, Tratt D M, Schichtel B A, et al. 2001. Asian dust events of April 1998. Journal of Geophysical Research, 106(D16): 18317-18330.

IPCC. 2007. Climate Change 2007-The Physical Science Basis. New York: Cambridge University Press, 171-177.

Kumar P, Fennell P, Britter R. 2008. Effect of wind direction and speed on the dispersion of nucleation and accumulation mode particles in an urban street canyon. Science of the Total Environment, 402(1): 82-94.

Leinen M, Prospero J M, Arnold E, et al. 1994. Mineralogy of aeolian dust reaching the North Pacific Ocean: 1. Sampling and analysis. Journal of Geophysical Research, 99: 21017-21023.

Li K, Wang Y J, Wang T, et al. 2010. Vehicle pollution emission inventory research in Urumqi city. Research of Environmental Sciences, 23(4): 407-412.

Li J, Zhuang G S, Huang K, et al. 2008. Characteristics and sources of air-borne particulate in Urumqi, China, the upstream area of Asia dust. Atmospheric Environment, 42: 776-787.

Li J L, Zheng Y P, Liu Z Q. 2007. Relationship between the low altitude temperature stratification and the heating period atmospheric pollution in Urumqi city. Journal of Arid Land Geography, 30(4): 519-525.

Li R, Wang X. 2007. Effects of precipitation on air pollution in Urumqi city. Journal of Desert and Oasis Meteorology, 1(2): 13-15.

Li Z Q, Edwards R., Thompson E M. 2006. Seasonal variability of ionic concentrations in surface snow and elution processes in snow-firn packs at the PGPI site on Urumqi glacier No. 1, eastern Tien Shan, China. Annals of Glaciology, 43: 250-256.

Liang Y, Liu X C, He Q, et al. 2008. Analysis on total dust fall during spring and summer in Xinjiang. Journal of Desert Research, 28(5): 992-995.

Mamtimin B, Meixner F. 2007. The characteristics of air pollution in the semi-arid city of Urumqi (NW China) and its relation to climatological process. Geophysical Research Abstracts 9, 06357.

Mamtimin B, Meixner F. 2011. Air pollution and meteorological processes in the growing dryland city of Urumqi (Xinjiang, China). Science of the Total Environment, 409: 1277-1290.

MEP (Ministry of Environmental Protection, China). 1994. Ambient Air Determination of Dustfall Gravimetric Method (GB/T 15265-1994). Beijing: Standards Press of China.

MEP (Ministry of Environmental Protection, China). 1995. Ambient air determination of total suspended particulates Gravimetric method (GB/T 15432-1995). Beijing: Standards Press of China.

Okada K, Kai K. 2004. Atmospheric mineral particles collected at Qira in the Taklamakan Desert, China. Atmospheric Environment, 38(40): 6927-6935.

Prospero J M, Uematsu M, Savoie D L. 1989. Mineral aerosol transport to the Pacific Ocean. Chemical Oceanography, 10: 188-216.

Sassen K. 2002. Indirect climate forcing over the western US from Asian dust storms. Geophysical Research Letters, 29: 1465-1469.

Shao Y P. 2000. Physics and Modeling of Wind Erosion. Dordrecht: Kluwer Academic Publishers, 5-62.

Uno I, Eguchi K, Yumimoto K. 2009. Asian dust transported one full circuit around the globe. Nature Geoscience, 2: 557-560.

Urumqi Municipal Bureau of Statistics. 2013. Urumqi Statistical Yearbook 2013. Beijing: China Statistical Press, 91-92.

Wang L, Xia D S, Yu Y, et al. 2010. Magnetic properties of urban dustfall in North Xinjiang and its environmental significance. Journal of Desert Research, 30(3): 699-705.

Wang T, Yan C Z, Song X, et al. 2012. Monitoring recent trends in the area of aeolian desertified land using Landsat images in China's Xinjiang region. Journal of Photogrammetry and Remote Sensing, 68: 184-190.

Wei W S, Gao W D, Shi Y G, et al. 2004. Influence of climate and environment change on dust storms in Xinjiang, China. Journal of Arid Land Geography, 27(2): 137-141.

Xinjiang Department of Environmental Protection. 2012. "Blue Sky" project achieved progresses in Urumqi, capital city of Xinjiang, China. [2013-09-20]. http://www.xjepb.gov.cn/tabid/787/InfoID/ 390237/frtid/40/Default.aspx.

Xinjiang Statistical Bureau. 2012. Xinjiang Statistical Yearbook 2012. Beijing: China Statistical Press, 60-225.

Xuan J, Sokolik I N. 2002. Characterization of sources and emission rates of mineral dust in northern China. Atmospheric Environment, 36(31): 4863-4876.

Yang L P, Chen F H. 2002. Study on the source apportionment of atmospheric dust pollutants in Lanzhou. Acta Scientiae Circumstantiae, 22(4): 499-503.

Yu H B, Remer L A, Chin M, et al. 2012. Aerosols from overseas rival domestic emissions over north America. Science, 337: 566-569. 